\title{
Feminist Editors and the New Girl Glossies: Fashionable Feminism or Just Another Sexist Rag?
}

\author{
By: Jessalynn Keller ${ }^{1}$, MJ, (UBC) BA (Sask)
}

\author{
Affiliation Address: \\ The Graduate School of Journalism \\ The University of British Columbia \\ Sing Tao Building, 6388 Crescent Road \\ Vancouver, BC, CANADA \\ V6T $1 Z 2$
}

Email: jessalynn.keller@gmail.com

Phone: (1) 512-461-2221 (cell)

\footnotetext{
${ }^{1}$ Present University Address: The Dept. of Radio-Television-Film, The University of Texas at Austin, 1 University Station A0800, Austin, TX, USA 78712-0108 phone: 512471-3532 fax: 512-471-4077 Home address: 4600 W. Guadalupe Street. Apt. B343, Austin, Texas, 78751
} 


\begin{abstract}
Media critics and feminists have long criticized teen magazines for providing limited substance and promoting a traditional view of femininity. This article challenges this assumption by using a critical discourse analysis to examine the production of girl glossies. Through interviews with four New York teen magazine editors, I unpack some of the contradictions embedded in editors' identifying as feminists while creating a cultural product often deemed anti-feminist. My findings suggest that editors combine practical strategies with a distinctively "third wave ethic" to navigate between corporate and cultural expectations in order to integrate a popular feminism into the magazine content. This third wave ethos however, tends to yield a conception of feminism as primarily a celebration of individual agency, neglecting a larger analysis of structural barriers and power relations. While editors have some success in refocusing teen magazines as sites for individual empowerment, I argue that this is not enough to truly empower teen girls and to challenge inequalities on a societal scale.
\end{abstract}

Keywords: girls' studies, media, popular culture, third wave, post-feminism 


\section{Introduction}

Traditional feminist academic analysis has theorized that feminism and popular

3 culture are in opposition to one another, assuming that because we live in a patriarchal

4 society and mainstream media outlets are primarily controlled by men, pop culture

5 typically appeals to the "male gaze" and, more broadly, reflects the sexist nature of our

6 society. Obviously, this has been viewed as problematic for women individually and for

7 feminism as a collective movement. One such area of critique has been feminist research

8 into teen magazines, which has primarily focused upon images of the female body and

9 traditional gender socialization in both editorial content and advertising. Over the past 30

10 years, feminist scholars have shed light on the ways in which teen girls are unrealistically

11 portrayed in mainstream girl magazines as a result of patriarchal notions of beauty,

12 sexuality, and success (Kilbourne,1999; Wolf,1991; Faludi,1991, Currie, 1999). While

13 this research has been incredibly valuable in highlighting the sexist nature of much

14 mainstream teen media, it did not necessarily reveal the complexities embedded in

15 contemporary girls' magazines and other forms of popular culture.

16 In response to this research, cultural studies feminists began to look at women's

17 and teens' magazines from a new perspective by understanding them as women-centered

18 texts that offer women pleasure and a chance to engage in utopian fantasies (Currie,

19 1999; Winship, 1991). Scholars began to understand the celebration of femininity found

20 in the pages of women's magazines as a source of pleasure, escapism, and validation for

21 their readers. Gill (2007) cites the early 1980s work of Tania Modleski (Loving with a

22 Vengeance) and Janice Radway (Reading the Romance) as key early texts of this

23 tradition. In this framing, readers become active cultural agents rather than merely

24 passive absorbers of corporate culture. This reconceptualization complicated the idea of

25 mainstream magazines as having a solely negative effect on women and opened the

26 debate for a more complex discussion about the role of women's and teen magazines in

27 the lives of women and girls (Gill, 2007).

28 This paper is situated within this continuing debate amongst feminist scholars.

29 However, my goal is to shift the discussion away from debating the merits and drawbacks

30 of teen magazines' content, toward examining the production of teen magazines and the

31 connection between feminist politics and the politics of production - an important but 
32 often overlooked factor in feminist research on media. Very few academic studies of

33 popular magazines examine who is writing and editing the publications and how their

34 work is shaped and contrained by cultural and economic factors (Jaques, 2004; Currie,

35 1999; Evans et al, 1991; Pierce, 1990; McRobbie, 1991).

$36 \quad$ My research addresses this gap by exploring connections between editorial

37 processes and the final printed page, utilizing structured qualitative interviews with four

38 New York-based magazine editors as my methodological approach. I was able to gain

39 access to editors through my social connections while interning at several New York

40 magazines in 2006. Editors were chosen based on their experience working at teen

41 magazines and their availability for an interview. All of the editors are working, or have

42 worked in the past, at mainstream teen publications based in New York City. Among

43 them, they have worked in a number of positions, including Beauty Director, Beauty

44 Assistant, Associate Editor, freelance writer, and Health and Beauty Editor. One of the

45 interviews was conducted in person in New York, two were conducted over the phone,

46 and one was conducted via email.

47 In what follows, I explore the following questions. Do any of the editors consider

48 themselves feminists - and, if so, what does that label mean to them? What challenges do

49 self-defined feminist editors encounter when working at a mainstream publication? How

50 much agency and editorial freedom do they have within the corporate magazine

51 environment? What strategies do they use to incorporate feminist content, as defined by

52 the editors themselves, into the magazine? And finally, to what degree do the editors

53 succeed in bringing a feminist perspective to their work and to the magazines they

54 produce?

\section{Literature Review}

57 Throughout the 1990s, several cultural developments added new insight into the 58 ongoing feminist debate about the potential benefits and harms of mainstream magazines

59 aimed at women and girls. The advent of third wave feminism is often dated to Rebecca

60 Walker's 1992 essay in Ms. called "Becoming the Third Wave," in which she located

61 herself as part of a new, re-energized generation of feminists wanting a feminism which

62 they felt spoke more to their own experiences (Lorber, 2005; Karlyn, 2003). The third 
63 wave grew into a complex movement and there remains considerable confusion amongst

64 feminists and non-feminists alike about what specifically defines the third wave. Most

65 feminist theorists agree that the third wave prioritizes the entitlement of each individual

66 to define feminism for herself, which leads to an embracing of contradiction, conflict, and

67 messiness when it comes to agreeing on a specific third wave agenda (Dicker and

68 Piepmeier, 2003; Heywood and Drake, 1997; Henry, 2005). However, the engagement

69 with personal and political transformation and a focus on grassroots activism remain

70 essential parts of the movement (Dicker and Piepmeier, 2003; Baumgardner and

71 Richards, 2000).

72 According to the commonly-used "wave" metaphor, the first wave of feminism

73 refers to the movement of the late $19^{\text {th }}$ and early $20^{\text {th }}$ centuries, which revolved largely

74 around suffrage. The second wave refers to the late 1960s and 1970s (what is commonly

75 referred to as 'the feminist movement') and, as I've outlined above, the third wave refers

76 to the more individualistic feminist movement of the 1990s and beyond. As many

77 scholars have noted, however, there are serious problems with feminism's continual

78 usage of the wave metaphor (McRobbie, 2009; Dicker and Piepmeier, 2003). Among

79 other things, this model incorrectly implies a straightforward, linear movement of a

80 singular "feminism", fails to recognize the complex inter-relatedness of different

81 feminisms, and ignores the many commonalities between feminists of different

82 generations (McRobbie, 2009; Dicker and Piepmeier, 2003). While I have chosen to use

83 the "wave" model for the sake of simplicity when referring to different feminist points of

84 view loosely associated with different generations and historical periods, I do not wish to

85 suggest that the second and third waves of feminism are separate, conflicting groups of

86 women. Instead, I hope that my discussion will help distinguish a variety of feminist

87 perspectives and how they meet and depart from one another.

88 During the 1990's, third wave feminists adopted popular culture as a site not only

89 for feminist critique, but also for potential empowerment of women. Around this time

90 popular culture itself was becoming more girl-centered, with girls becoming the focus of

91 many pop culture products in music, television, and movies (Hopkins, 2002). This was

92 the era when the Spice Girls sold millions of albums with their fun "Girl Power"

93 message, and a slew of other powerful pop culture girl heroes like Xena Warrior Princess 
94 and the PowerPuff Girls ruled the cable networks (Hopkins, 2002). This "mainstreaming"

95 of girlhood has led some scholars to characterize much of the popular culture of this

96 period as "girl culture" (Karlyn, 2003; Hopkins 2002). Some feminists began to ask

97 whether teen magazines, along with other feminine-scripted items such as Barbie dolls,

98 make-up, and fashion, could be sites for female empowerment and resistance to

99 patriarchal notions of the feminine as weak (Karlyn, 2003).

100 Many feminist scholars see this explosion of mainstream girl culture as related to

101 the development of third wave feminism (Karlyn, 2003; Dicker and Piepmeier, 2003).

102 The third wave had always celebrated femininity and girlhood, and the developing

103 mainstream interest in "girl power" in the mid-1990s married easily with the third

104 wave's brand of "fun," pop-culture-based feminism. "We call this intersection of culture

105 and feminism 'Girlie.' Girlie says we're not broken, and our desires aren't simply booby

106 traps set by patriarchy," write Jennifer Baumgardner and Amy Richards in their third

107 wave bible, Manifesta: Young Women, Feminism, and the Future (2000: 136). "Girlie

108 encompasses the tabooed symbols of women's feminine enculturation - Barbie dolls,

109 makeup, fashion magazines, high heels - and says using them isn't shorthand for 'we've

110 been duped'." All of a sudden, objects and cultural artifacts once deemed sexist and

111 derogatory toward women were being looked at with a fresh eye as mainstream girl

112 culture and third wave feminism converged in the realm of popular culture.

113 But "girl culture" was not without its critiques, from both within and outside

114 feminist communities. Many feminists viewed the third wave's adoption of a pop culture

115 centered celebration of girlhood and, as a result, its easy adaptation to the mainstream

116 "girl power" phenomenon as selling out to capitalist commodification, politically void,

117 and not useful for feminism as a social movement (Hains, 2004; Taft, 2004; McRobbie,

118 2009). Rebecca Hains (2004) argues that while "girl power" positively reflects a valuing

119 of the girlish, it does not challenge or even subvert mainstream femininity. She also

120 criticizes it for encouraging consumption rather than a do-it-yourself ethic, for

121 emphasizing the personal in ways that seem apolitical, and for excluding girls whose

122 bodies do not fit the thin, athletic mold. McRobbie (2009) points out that "girl power"

123 has very limited capacity to make sense of the way that gender inequalities affect real-

124 world social issues. She writes (2009:158), "it is not just a question of [girl power] being 
125 inimical with recent directions in feminist theory, it is also ill-equipped to deal with war,

126 with militarism, with 'resurgent patriarchy,' with questions of cultural difference, with

127 race and ethnicity, and notably with the instrumentalisation of feminism on the global

128 political stage." Other social commentators criticize the "girl power" trend for its

129 hijacking and trivializing of feminism. For example, in a 1998 article for Time, journalist

130 Ginia Bellafante (1998:55) described today's "pseudo-feminism" as "stylish fluff" that

131 has made feminism "devolve into the silly."

132 At the same time though, feminists such as Jennifer Baumgardner see the

133 incorporation of some third wave ideas into the mainstream as a sign of progress. In a

134 December 2006 phone interview, Baumgardner said,

135 I think [third wave feminism and "girl power"are] on the same continuum,

142 The merits of 'girl power' and its connection to third wave feminism remain contentious

143 issues for many feminists. However, it is worth noting that girl culture played an

144 important role in refocusing pop culture toward teen girls, bringing ideas about personal

145 empowerment into the mainstream, and creating a public dialogue about feminism

146 (Driscoll, 1999).

147 Whatever its implications from a feminist point of view, this new focus on girls

148 meant that girls were now seen as a valuable demographic in the capitalist marketplace

149 (Karlyn, 2003). As a result, media companies scrambled to pump resources into their teen

150 titles, leading to a revival of the teen magazine market. For example, seventeen teen

151 magazines launched in 1998, in comparison to only five in 1990 (Min Online, 2006). The

152 staff at teen publications were also affected by this new cultural context, as women who

153 grew up with third wave feminist values within the "girl power" climate of the 90s began

154 entering the workforce, including taking up editorial positions at blossoming teen

155 magazines. Several of the editors I interviewed spoke of being very influenced by the

156 feminist pop culture of the 90s, including "angry girl music" of the Riot Grrrls and 
157 publications such as Sassy. Thus, it is reasonable to expect that this influence may be one

158 factor informing their current magazine work.

\section{Theoretical and Methodological Framework}

161 I employ a critical discourse analysis to examine my interviews with the editors

162 about their experiences and practices working in the mainstream magazine industry.

163 Critical discourse analysis "provide[s] ways of challenging systems of knowledge and

164 power by interrogating and contextualizing dominant discourses" (Carroll, 2004: 225).

165 Commonly used in cultural studies and media studies, critical discourse analysis allows

166 for an explicit focus on the power relations and ideology behind not only a text itself, but

167 also the social context framing the text (Carroll, 2004). Thus, it is a useful tool to help

168 place the editors' comments within their broader social, political, and economic context.

169 My analysis is also situated within an understanding of third wave feminism and

170 the theory that informs it. Third wave theory tends to be racially and sexually inclusive,

171 global, and ecological in perspective, with a strong emphasis on critical race theory,

172 queer theory, and post-colonial theory (Karyn, 2003). Third wave feminists are "media-

173 savvy" and will often take a postmodernist orientation towards popular culture (Heywood

174 and Drake, 1997). Consequently, they claim the realm of pop culture as a natural site of

175 identity-formation and empowerment, one that provides an assortment of images and

176 narratives that can be used less as a means of representing reality, and more as "motifs"

177 available for contesting, rewriting, and recoding (Karyn, 2003). In this sense, third wave

178 theory resembles the cultural studies approach of the Birmingham School which,

179 according to Suheyla Kirca, sees media texts as "central sites in which negotiation over

180 gender takes place, and in which contradictory cultural representations of gender are

181 accommodated, modified, reconstructed, and reproduced" (2001: 459). Thus, popular

182 culture is understood as a field of both conflict and contestation (Hall, 1981, as cited in

183 Kirca, 2001).

184 For example, during the 1990s, many third wave feminists began to criticize

185 second wave feminists' supposed disdain for pop culture and instead began to

186 reconceptualize pop culture from an ironic, media-savvy standpoint, embracing it as a site 
for potential feminist resistance (Heywood and Drake, 1997). This strategy became a distinguishing feature of this "new" kind of feminism. Karlyn (2003: 10) writes,

While retaining the critique of beauty culture and sexual abuse from the Second Wave, young women have complicated the older feminist critique of the male gaze as a weapon to put women in their place, and instead exploit the spotlight as a source of power and energy. Thus girls do not see a contradiction between female power and assertive sexuality. Girl Power icons can dress in provocative clothing while demonstrating fierce physical prowess (such as Buffy,the Vampire Slayer) or chant the virtues of female power and solidarity while wearing Wonder Bras (like the Spice Girls).

twenty-first century, older feminists must recognize the importance of popular culture in the lives of girls and reposition the feminist conversation on the terrain of popular culture "where young women today are refashioning feminism toward their own ends." Baumgardner also stresses the importance of pop culture for contemporary feminism, claiming,

We're constantly engaging with pop culture and therefore feminists need to not opt out. Pop culture feminists of this generation have learned that pop culture is something good to indulge in, and that we can influence it. It's not just something to critique, it's something to create, and something to talk back to, and something to love, and something to zone out to.... Third wave feminists have a healthy relationship to pop culture and see it as a tool. And it is a tool - we are in a communications revolution right now and pop culture is a big part of that. It would be silly to say that politics can be the only area where our battles can be fought.

\section{In Girl Talk: Adolescent Magazines and Their Readers, Currie (1999)}

characterizes ongoing feminist debates about women's and teen magazines as based on opposing views of power, or as Gill suggests in a related vein, as reflecting different emphases on "oppression versus pleasure" (2007: 195). On one side of the debate is the view that media, including magazines, continually produce a script of traditional femininity that helps to reproduce dominant gender ideologies and the patriarchal subordination of women (Tuchman, 1978; McRobbie, 1977; Williamson, 1978; Winship, 1978). For example, Gaye Tuchman's 1978 analysis of mainstream media concluded that women were being damaged by 'absence', 'trivialization', and 'condemnation' (as cited in Gill, 2007: 11). In this view, the texts are understood as problematic and in need of 
224 thorough critique, and women's enjoyment of them is seen as women being "duped" into 225 endorsing their own subordination.

226 On the other side is the more contemporary view that magazines provide a forum

227 for the recognition and validation of women's pleasure and fantasies and, as Currie notes, 228 are "not to be mistaken for reality" (1999: 53). According to this approach, readers 229 remain in control of textual meanings and their consumption (Modleski, 1982; Geraghty,

230 1991). One of the earliest examples of this perspective was Tania Modleski's (1982)

231 research on soap operas and romances, in which she argued that these texts are more than

232 escapist fantasies, but rather offer women engagement with real problems in complex and

233 contradictory ways, "offering temporary, magical, fantasy or symbolic solutions" (Gill,

234 2007: 14).

$235 \quad$ Neither perspective, however, takes into account the possibility of feminists

236 negotiating the texts themselves by producing pop culture products (such as magazines)

237 to create feminist meanings and resistance, which would acknowledge both pleasure and

238 ideology as intimately related and offer a more complicated understanding of media

239 reception $($ Gill, 2007). This new perspective also acknowledges the role of media

240 production in meaning-making - in this case, who is producing the magazines? - as

241 opposed to limiting one's analysis to textual meanings and audience reception. The

242 ability to take on this different analytic perspective is not limited to the third wave;

243 however, because of the third wave's engagement with popular culture, as well as its

244 tendency to embrace a certain amount of contradiction and "messiness", it presents a

245 potentially useful framework for editors to use to incorporate feminist content into their

246 respective mainstream publications. Critical discourse analysis is a useful tool to analyze

247 not only content but also the intentions and strategies of the editors who create the

248 publication, in an attempt to better understand how third wave discourse influences both

249 editorial processes and the final content in the magazine. I am not able to explore the way

250 the texts are read and understood by readers themselves at this time.

\section{Results and Discussion}


My results suggest that self-defined feminist editors working at teen titles employ 255 practical strategies informed by a distinctively "third wave ethic" to integrate elements of

256 a popular feminism into their magazine content, despite corporate and cultural

257 inhospitability to such content. This third wave ethos, however, produces content 258 primarily concerned with making feminism a celebration of individual agency, while

259 lacking political rigor and neglecting a larger analysis of structural barriers and power

260 relations. While editors have some success in refocusing teen magazines as sites for

261 individual empowerment, I argue that this is not enough to truly empower girls and to

262 challenge inequalities on a societal scale.

\section{The labeling issue: Are these editors feminists?}

As Currie (1999) and Evans et al (1991) have shown, teen magazines often focus on fashion, beauty, and heterosexual romantic relationships. For this reason, it is tempting to assume that teen magazines are anti-feminist, and furthermore that the

268 women who work at these magazines must be anti-feminist as well. I was thus surprised

269 to discover, as I began my research, that all four of the editors I interviewed self-

270 identified as feminists, and all noted that this identification was reflected in their writing

271 and/or editing work. For example, an Associate Editor at CosmoGIRL claimed that, "I do

272 consider myself a feminist, and I think that I just bring that to anything that I write.”

273 Several of the editors mentioned that it was important for them to identify

274 themselves as feminists in hopes of undermining prevalent stereotypes of feminists as

275 militant, man-hating women. For example, another editor, a former Health and Beauty

276 Editor at Teen Vogue said,

I would say that I call myself a feminist because I think it's important to realize that the feminist movement is NOT over...I also think it's important to make people realize that feminists aren't the stereotypical man-haters. I'm

285 In this sense, editors see themselves as helping to break down the stereotype that "real 286 feminists" don't wear lipstick, and thus opening up the public perception of feminists. 
While the editors used the term "feminist" to describe themselves, they were 288 vague about how this label specifically applied to their roles as magazine editors and the

289 stories they write and edit. Instead editors focused on the mainstream stereotypes of

290 feminists, primarily in terms of appearance (e.g., non-fashionable) and personality (e.g.,

291 uptight and angry), and positioned themselves as contradicting these stereotypes. While it

292 is indeed important to challenge these limiting stereotypes, some of the editors seemed to

293 emphasize the claiming of a feminist identity without addressing what political beliefs,

294 values, and commitments are involved in that identity - a question arguably more

295 important than whether a feminist wears fashionable clothes or not.

296 Dicker and Piepmeier (2003: 17) characterize this common lack of political rigor

297 as a "feminist free-for-all", meaning that everything and everyone can fit under the

298 feminist umbrella regardless of what they actually think, do, or believe. As a result,

299 feminist politics become diluted in an attempt to complicate and broaden the general

300 understanding of feminism. This tendency has, unfortunately, characterized much third

301 wave writing and has muddied third wave conceptions of what a feminist is (Dicker and

302 Piepmeier, 2003). While the third wave has helped make feminism accessible to a broad

303 range of people who may have previously been uncomfortable with the term, it must not

304 empty feminism of its political content in favor of adopting a non-threatening style that

305 merely conforms to mainstream notions of beauty and femininity.

306 To highlight these complications around the definition and boundaries of

307 feminism, I will refer to the editors I interviewed as being self-identified feminists, rather

308 than attempting to say in some definitive way whether they are feminists or not.. Thus, I

309 hope to position the term "feminist" itself as up for critique and contestation.

\section{Successes and challenges: Trojan horses in Manhattan's media landscape}

312 The editors have enjoyed some success in introducing feminist content into their

313 respective publications. All of them spoke enthusiastically about recent well-written

314 stories dealing with feminist issues. "I would say that teen magazines handle all the hot

315 button issues reasonably well, they try to be very responsible," one editor maintained.

316 She noted that she has written on topics such as abortion, date rape, and dating violence

317 for teen publications. Other feminist content discussed by editors includes a story about 
comprehensive sex education and teen activists who are trying to get it at their schools,

319 an expose on sorority life, and a profile of three pregnant teen girls and the choices they 320 made about their pregnancies.

321 Sexual health is a topic that most editors agree is covered reasonably well by teen 322 magazines. Editors mentioned stories on STD's, gynecological visits, birth control, and

323 HPV as recent examples of stories that made the health sections of teen publications

324 feminist in orientation. One argued, however, that while publications print sophisticated

325 sexual health pages, there are still very few articles written about sexuality itself.

326 “There's so much stuff written about STD's and all this stuff associated with sex," she

327 says, "but very little about sex itself, which I think is really confusing for teenagers. I see

328 very few magazines doing that [talking frankly about sex] because I think they're nervous

329 to say anything other than, you know, 'wait until you're in love - abstinence!'”

330 The topic of body image also drew a mix of opinions from editors. While most

331 agreed that positive body image stories are written - diet stories, for example, are banned

332 from most teen magazines -- a few had doubts about the stories hitting all the right issues.

333 For example, one editor wrote and edited many stories about body image for Teen Vogue,

334 dealing with issues such as competitive dieting, parents who judge their daughters'

335 bodies, and how girls of different ethnicities have different kinds of body image struggles

336 - issues, she maintained, that are important but often ignored. "Most magazines cover

337 [body image] ad nauseum, but I think they often do a bad job of it. They talk about

338 anorexia and bulimia, which are important problems, but most girls aren't anorexic or

339 bulimic - but they do have disordered eating that really affects their lives."

340 All of the editors were frank about the challenges of being feminists in the

341 mainstream magazine industry. The biggest challenge identified by editors is the

342 corporate culture that permeates an industry dominated by the mega-corporations of

343 Hearst, Advance (which owns all Condé Nast titles), Time Warner, and Meredith

344 Corporation. According to "The State of the News Media 2010," a report released by the

345 Project for Excellence in Journalism, these four companies together own close to three-

346 quarters of all American-published magazines (Project for Excellence in Journalism,

347 2010). The predominant concern amongst editors was the conservative nature of

348 advertisers, which affects all aspects of the production process - pitching, reporting, 
writing, and editing stories. Several of the editors revealed that particular topics they

350 want to write about, such as abortion and sex, just don't get approved by senior editors

351 due to their "controversial" nature.

352 Another editor, who has held prominent posts such as Beauty Director at Nylon

353 and Beauty Assistant at Teen Vogue, and who now works as a freelance contributor to

354 several popular women's magazines, was forthcoming about the constraints under which

355 editors must work. "It's hard to be a commercially successful magazine and have strong

356 opinions because you want to appeal to such a broad audience and so many advertisers

357 are very conservative, Midwestern companies with Christian values that just do not want

358 to see certain content in the magazine," she said. Even planning for an article on the

359 Equal Rights Amendment, a story idea that has been simmering in the CosmoGIRL!

360 office for over a year, has been a delicate game of give and take, according to the

361 CosmoGIRL editor. "The challenge is, how do we pitch it? How do we package it?

362 Budgeting is a problem, in terms of getting the pages dedicated to it." This comment

363 alludes to the integrated nature of advertising and magazine content. For example, an

364 article on the ERA amendment will not attract advertising dollars like a beauty story

365 might, presumably because many of the advertisers in teen magazines sell cosmetics and

366 would much rather see their advertisements beside an article that complements what

367 they're selling.

368 Intensifying corporate control of media has been well documented by media

369 scholars over the past three decades (Bagdikian, 1983, 2004; Herman and Chomsky,

370 1988; McChesney and Foster, 2003; McChesney, 2008). This increased corporate control

371 not only means more media conglomeration, but also an increased presence of

372 advertising in media industries. In fact, advertising dollars have become the primary

373 source of revenue for many media industries, and media outlets that do not attract

374 advertisers find themselves at a significant disadvantage in the marketplace (McChesney

375 and Foster, 2003). This increased economic clout means that advertisers themselves are

376 making editorial content demands and if media firms do not accommodate their wishes

377 they are threatened with pulled advertising money. McChesney and Foster (2003: 4)

378 argue,

379 
We are rapidly moving to a whole new paradigm for media and commercialism, where traditional borders are disintegrating and conventional standards are being replaced with something significantly different. It is more than the balance of power shifting between media firms and advertisers; it is about the marriage of editorial/entertainment and commercialism to such an extent that they are becoming indistinguishable.

Magazines are at particular risk when it comes to corporate control over editorial content, as magazines have historically been profitable for their owners, unlike news media outlets which have never been viewed as particularly profitable and have served more of a public service function. For example, one of Conde Nast's popular women's magazines, Lucky, is dictated entirely by advertising, from the design of editorial pages to editorial copy, which is always linked to specific products (McChesney and Foster, 2003). As a result of this close relationship between editorial departments and advertisers, media becomes more about selling goods and propping up capitalism than about solving social problems or promoting values like diversity, equality, community, and human development (McChesney and Foster, 2003). This problem can be clearly seen in editors' comments regarding advertising in their publications.

Corporate control reaches beyond merely the general topic of a proposed article. Once the original story idea is approved, editors are restrained in the type of language they can use, the illustrations that accompany their stories, and the number of pages devoted to a story. All of the editors agreed that printing the "f-word" - feminism - was a huge problem for mainstream publications. While editors are writing stories that deal with female empowerment, printing the word "feminism" or an open declaration of a feminist perspective remains taboo at all mainstream teen glossies. One editor explains, People don't understand the definition of feminism anymore. You're nervous to say it. I know at more corporate magazines you're nervous to print it, so it's hard. I wish we could say it more so that it becomes an ok word. But that's not the only word that's like that - vagina is another one, you never see that in magazines.

Editors also spoke of the standard teen magazine format as posing a challenge to their efforts to incorporate feminist pieces, as complex stories must be adapted to a very limited page space and word count. Other challenges include working with other departments to ensure the maintenance of a feminist tone, and making sure the piece's 
415 original message is preserved after the editing process. One editor, who has never been

416 on staff at a teen publication but has done freelance work for several mainstream teen and

417 women's magazines, said that she occasionally struggles to tell "fascinating political

418 stories" in a way that fits into the teen magazine mold. "You can't go in there and be like,

419 'I want you to run this story that really should be run in The Nation in your publication,"

420 she said. She also spoke of the financial challenges that freelance feminist writers

421 experience when choosing what stories to tell, explaining,

I can do a relationship story, and it would take a day to write and I would make a lot of money. If I did a reported story about a feminist issue that I care about it could take a month to write and pay the same amount of money, so I guess the challenge is still wanting to do those stories, given how much more of a struggle they are.

Editors spoke of the continuing challenges that they often face, having run stories deemed more "controversial," once the magazine hits the newsstand. For example, "Sister to Sister" is a regular CosmoGIRL! column in which an editor addresses a relevant social issue based on her own personal experience. The CosmoGIRL editor spoke of a "Sister to Sister" column she wrote for the September 2006 issue in which she discussed the September 11 terrorist attacks and how they affected her understanding of world politics, and encouraged girls to be more aware of international politics and social issues

437 response to the article. "Most of the girls still live at home with their parents and they feel 438 very passionately about things and they still align themselves with their parents in many 439 ways," she admitted, adding "Middle America is still very conservative, it's red country."

440 Because teen magazines rely heavily on reader contributions (often readers are 441 interviewed and their quotes featured in stories) comments and concerns from readers 442 are taken seriously and often have an impact on future stories. At Seventeen, for example, 443 all editors in the features department are given a daily synopsis of reader responses which 444 have come in through snail mail, email, and the magazine's MySpace and Facebook 445 pages. These comments are used to gauge readers' opinions, which in turn are used to 446 determine future suitable stories. As a result, conservative readers and their parents can 447 become roadblocks to future feminist content in the magazine. 


\section{Undercover strategies and the third wave ethic}

450 My interviews suggest that editors have developed certain practical strategies to

451 navigate and overcome the challenges of incorporating feminism into mainstream

452 publications. Most of these strategies are based upon what I call a "third wave ethic,"

453 meaning that the tactics employed are related to some of the tenets of third wave

454 feminism. I will briefly explain these connections in the course of discussing the editors'

455 strategies, which fall under the three general themes of: (1) Integrate yourself, (2)

456 Disguise feminism, and (3) Make feminism fun.

457 Several of the editors understood their participation in the mainstream media as

458 one crucial strategy for getting more feminist content into the mainstream media. This

459 participation was characterized as a "sneaky," under the radar infiltration. The former

460 Teen Vogue editor said,

461 I implement feminist ideals into my work by just being in the mainstream media. I think far too many feminists stick to alternative media. I love the alternative media but you're preaching to the converted. Being an editor at Teen Vogue and The New York Times - I have a much broader audience. And I think one of the keys is to take a job in the mainstream media and integrate yourself. Make other editors and writers like you. Then when you start pitching feminist content, they'll be more open to it. They already like you. They think you're smart. They trust you. That's how to get feminist content into the mainstream.... I'm glad I've had a mainstream career... I like being a Trojan horse.

472 This strategy differs somewhat from second wave feminist tactics, as some second wave

473 feminists emphasized the importance of establishing separate feminist institutions away

474 from the mainstream (Baumgardner and Richards, 2000). An obvious example would be

475 the launch of $M s$. in 1972, a magazine with the overt agenda of advancing feminist goals

476 and reporting on women's issues. In our interview, Baumgardner (who once worked at

477 Ms.) explained that, in contrast, "the third wave is bringing feminism into other

478 institutions... it's an integrating force.” This strategy builds upon the third wave's

479 interaction with mainstream institutions, including the media and the popular culture and 480 entertainment industries. 
However, this interaction must be examined with an eye to the structural context

482 of corporate capitalism within which it takes place. McRobbie (2009: 5) questions

483 whether individual women - even those who may be feminist-influenced graduates or

484 schooled in feminist thought - can actually maintain a commitment to feminist issues

485 within the confines of the corporate magazine world. She critiques her own past naiveté,

486 indicating that she "did not fully engage with the way in which the battle for circulation

487 figures could see an editor sacked for displeasing a company with a lucrative advertising

488 contract." She also notes that the critique of capitalism which had been a defining feature

489 of past socialist-feminist scholarship seems to have been replaced in contemporary

490 feminist thought with a desire not only to participate in corporate capitalism, but also to

491 believe that a feminist agenda can be incorporated within the current frameworks of

492 capitalism.

493 It appears as though the editors whom I interviewed subscribe to this latter belief,

494 while nonetheless acknowledging the limitations of the context within which they are

495 working. While this may be a valid position, it fails to incorporate a thorough analysis of

496 the power relations that govern capitalism. For example, how does one's participation in

497 the corporate magazine world affect one's position to critique it? Can true feminist

498 content even be created in an environment that survives on maintaining hierarchical

499 power relations based on class, gender, race, and more? Without a thorough analysis of

500 the constraints imposed by the capitalist media context, I question whether "integration"

501 can be a truly revolutionary strategy.

502 Given the concern expressed by all the editors about advertisers and corporate

503 influence on content, it is not surprising that several of them mentioned "disguising"

504 feminist content as a crucial strategy. This strategy includes tactics such as "couching"

505 feminism within less threatening topics, such as entertainment stories, and labeling

506 feminist content as something else. In this sense, a lot of attention is paid to language, in

507 particular to avoiding the "f-word." The former NYLON editor explains explains, "You

508 can do it [mention feminism] at Teen Vogue now and then, but you're not going to see

509 issue after issue talking about feminism openly. I think it's a struggle for a lot of editors

510 to find ways to get it in - but I think they do. It's so much about how you label it, if you

511 label it something different it's ok, usually." 
The editor from CosmoGIRL! acknowledges that this is the strategy used at her

513 magazine. "I really do the feminist thing, but we don't throw the f-word out there at all,"

514 she said, "I think it's a scary word and I think it's a scary word for girls. Even for me

515 now, I hear the word, and it has so many connotations. We've actually had meetings

516 about this, about how we can strip the word of its bad rep." Instead, CosmoGIRL! editors

517 have decided to steer clear of the term and opt for less political terms such as

518 “empowerment." According to her it's part of a larger strategy to encourage girls to

519 empower themselves without making them call themselves feminists, despite the fact that

520 they're still engaging with feminist ideals. The strategy appeases advertisers and avoids

521 alienating girls who may be put off by the term, while still preserving editors' own beliefs

522 about the importance of feminist content.

523 The need to disguise feminism highlights the confusion about feminist identity in

524 particular, and about identity more generally, that the third wave continues to struggle

525 with (Dicker and Piepmeier, 2003). Some editors even suggested that the word

526 "feminism" may not be that important anymore. "It seems to be a term very much of an

527 era and so it feels dated sometimes to use the word feminist," one editor admitted. This

528 idea appears to play into the editors' presentation of feminist stories for adolescent girls,

529 who, editors acknowledge, may not have grown up with the term. "I've found that most

530 teenagers don't respond to it," one noted. "Part of that is because teenage girls have

531 experienced less sexism - they're doing better than boys in school, they are achieving

532 great things athletically, they are in charge of all kinds of extracurricular activities. They

533 haven't yet gotten out into the world where they may be better educated and have more

534 experience than their male co-worker, and yet making much less money."

535 In the September 2006 issue of CosmoGIRL!, the regular column "She's So

536 CosmoGirl" profiled Shaina Muñoz, a Hispanic girl who revealed that she often felt that

537 she didn't fit into her white, affluent, private high school. She decided that her classmates

538 could benefit from being educated on diversity issues and she wanted to help open up

539 discussion about issues such as race, ethnicity, sexual orientation, and socioeconomic

540 status in her school. After she submitted a proposal for an elective diversity class to

541 school administrators, her course was approved and Muñoz was named co-instructor

542 along with several teachers. Muñoz's story emphasizes the pervasive narrative found in 
543 the "She's So CosmoGirl" column - the ability of an individual to get motivated, take

544 action, and make a difference. Other 2006 "She's So CosmoGirl” profiles showcased

545 girls who have fought for freedom of speech, tackled gender bias in the technology

546 industry, and educated fellow students on their privacy rights, for example. These stories

547 all contain an individualist notion of activism within a larger celebration of individual

548 agency. The girls are touted as heroines with personal qualities and abilities that have

549 made them strong leaders, and the implication is that individual girls can make a

550 difference - a message that is empowering for readers because it suggests that this

551 success can be attained by any one of them.

552 This focus on individual agency as a driving force of activism highlights the third

553 wave ethic mentioned earlier. While feminist concerns such as diversity issues related to

554 race and class, consciousness raising, and the promotion of social change are all present

555 in the profile, these issues are not connected to a broader feminist agenda. Feminism is

556 not specifically mentioned (nor is any other organized, collective social movement) and

557 Muñoz does not describe herself as a feminist, despite clearly engaging in feminist work.

558 While the "disguising" strategy may seem effective or at least necessary, there is a

559 tension between editors' own identification as feminists and their practice of avoiding the

560 f-word. While avoiding using the word "feminism" may work as a short-term tactic for

561 getting certain content into the magazine (such as the abovementioned activist profile), it

562 is problematic because it eradicates many of the important parts of feminism while

563 undermining the editors' stated goal of challenging antifeminist stereotypes. The absence

564 of the word "feminism" implies that feminism is no longer needed. McRobbie (2009: 57)

565 argues that avoiding the word "feminism" has been central to "post-feminist" discourse in

566 popular culture, serving to instead promote a highly conservative form of "feminine

567 empowerment" which is depoliticized and "weighted towards capacity, success,

568 attainment, enjoyment, entitlement, social mobility, and participation."

569 By substituting the word "empowerment" for "feminism," the editors seem to

570 assume that these words have the same meaning, when this is in fact not the case:

571 "feminism" names a political critique and a collective movement, whereas

572 “empowerment" can name a merely individual condition. Unlike "feminism," the word

573 "empowerment" has no political implications, and consequently, carries with it no 
574 responsibility to critique structural inequalities like patriarchy or capitalism. In fact, the 575 word "empowerment" easily supports capitalism because it privileges individual action

576 and the individual's ability to change their own situation, rather than collective

577 movement or change, as was central to feminist and socialist movements (McRobbie,

578 2009). Gill (2007) argues that this language of individualism is common in women's

579 glossies and that the emphasis on personal solutions is at the expense of collective social

580 and political struggle. Furthermore, avoiding the word "feminism" also does not

581 encourage girls to become self-identified feminist women, which may only continue to

582 perpetuate many of the stereotypes about feminists that are currently prevalent.

583 Consequently, while this strategy may be the best possible option under the

584 circumstances, the editors' optimism about this tactic reveals that long-term social

585 changes may not be on the agenda of teen magazines. As a result I am doubtful that

586 disguising feminism will do much to contribute to meaningful, long lasting, feminist

587 changes.

588 All of the editors agreed on the importance of making feminism - whether so

589 labelled or not--"fun" for readers. This theme kept re-emerging in their examples as one

590 of the primary ways to successfully "sell" feminist content and ideals to teen girls.

591 Making feminism fun included tactics such as using pop culture and celebrities in their

592 pieces, integrating beauty and fashion tips in an empowering way, developing a

593 "girlfriend tone" with readers, and incorporating humor into pieces. One editor

594 mentioned that Sassy, a popular, now almost "cult" teen title that was cancelled in 1996,

595 was a great example of how feminism can be married with lighter, trendier topics:

596 The magazine wrote plenty of articles on why feminism was important, why the editors at the magazines were feminists. And yet, these stories ran in between fashion and beauty spreads. And this made feminism seem fun to teenage girls. Being a feminist didn't mean you didn't want to wear lipstick. And yet, Sassy's beauty coverage never made girls feel bad. There were no diet stories. There were no stories on why this season you had to have blonde hair. It made beauty fun. That's pretty feminist.

605 she seems to be implying that non-dogmatic beauty coverage that provides readers with

606 choice and consequently, "never made girls feel bad" for what they had or did not have 
607 was liberating. This is indeed true to a certain extent. Sassy did offer up more than one

608 image of beauty to their readers, including images that contradicted dominant standards

609 of beauty. For example, Sassy ran beauty stories about dying your hair with Jell-o and

610 often poked fun at normative beauty standards by running features like "13 Reasons Not

611 To Diet" and "Our First Annual Junk Food Taste Off." But while the magazine was more

612 diverse than its teen magazine competitors at the time and tended to promote body

613 acceptance within its copy, it still showed only thin models and girls in its pages (Jesella

614 and Meltzer, 2007).

615 While Sassy may have provided more beauty options to individual girls, the above

616 editor's comment lacks a critical analysis of consumption practices, as well as ignoring a

617 large body of feminist research that has pointed to the harmful effects of the fashion and

618 beauty industries on women and teen girls. The past decade has seen consumption

619 increasingly being promoted in popular culture as a liberating, feminist pursuit, such as

620 on the popular television show Sex and the City (Gill, 2007). In other words, the ability to

621 "charge it" is presented as women's exercise of choice, power, independence, and

622 agency. This type of "empowerment" conforms to the capitalist marketplace, which

623 thrives on the consumption of goods, and is also used by advertisers to attract teen girl

624 consumers. Gill (2007) argues that the emergent discourse of girl power in teen

625 magazines is tied to consumption, and especially to the consumption of beauty products.

626 For example, Negra (2009:119) cites an ad for Nair Pretty, aimed at 10- to 15-year olds,

627 which "suggests that the depilatory is a stubble-free path to empowerment." Thus, girls'

628 agency is often presented as explicitly tied to buying things with the promise that these

629 goods will give them social power and independence (Gill, 2007). Instead of focusing on

630 the real ways girls can obtain power, for example through leadership, education, artistic

631 and athletic pursuits, the focus on consumption not only makes false promises to girls,

632 but pushes them into the cycle of continually pursuing goods to boost their self

633 confidence. Thus, even when articles do focus on topics beyond fashion and beauty, they

634 are often quickly undermined by the magazine's overall message of empowerment

635 through consumption, conveyed in both the editorial copy and the advertisements.

636 A large body of feminist work has documented the harmful effects of the beauty

637 industry on girls and women (Wolf, 1991; Bordo, 1993; Jeffreys, 2005; APA, 2007). 
638 Research has also demonstrated that girls' readings of teen magazines center on images

639 of "beauty", rather than on the articles, even those giving advice about fashion, hair, and

640 make-up. Thus, girls are specifically concerned with the visual representations of the

641 ideal female body found in teen magazines, typically defined by "clear skin, a slim build

642 [and], developed bust" (Duke and Kreshel, 1998: 57). These images and their messages

643 have been found to have a profoundly negative effect on girls. For example, a 2007 report

644 by the American Psychological Association (APA) revealed that problematic models of

645 femininity, including sexual objectification and a narrow and unrealistic standard of

646 physical beauty, are very dangerous for girls. The results of continual exposure to such

647 messages include diminished cognitive and emotional abilities, mental and physical

648 health problems (including eating disorders, low self esteem, and depression), the

649 inability to develop a healthy sexuality, and diminished self worth (APA, 2007).

650 Increased rates of sexual harassment, sexual violence, and use of child pornography have

651 also been linked to media objectification of women and girls (APA, 2007).

652 These critiques, however, were disregarded for the most part by editors, who

653 assumed that simply by making beauty "fun" the potentially harmful effects of beauty

654 pages would be negated. Gill (2007) maintains that this is simply not the case, arguing

655 that regardless of how "fun" beauty is made, the notion that girls should be concerned

656 about their appearances and that beauty regimes are an essential part of "being a girl"

657 remains embedded in the prevalence of beauty pages in the magazines. Thus, girls find it

658 very difficult to "opt out" of this constructed femininity, with their self-esteem becoming

659 increasingly linked to how they perceive they look. Gill (2007: 188-189) writes,

Against this backdrop of a powerful beauty mandate for girls, 'fun' does not seem to capture even remotely the complexity of girls' relationship to their own bodies. Rather, the discourse is part of the shift from objectification to subjectification in which more and more of the normative requirements of femininity must be presented as freely chosen and pleasurable, and internally motivated rather than imposed or influenced by wider culture. 
669 Thus, by presenting beauty as a "fun choice" it appears that the problematic aspects of the 670 beauty industry have been removed, when in reality, the harm is merely being couched in 671 the language of celebrating choice, empowerment, and fun.

One editor talked about how CosmoGIRL! editors use pop culture references and 674 celebrities to make their regular "Project 2024" column more exciting. ("Project 2024" is 675 a question-and-answer interview with a leader who has achieved success in her field. 676 The column's overall goal is to get a CosmoGirl in the White House by the year 2024.)

677 "We try to sex it up a bit - and that's one of the challenges with feminism - making it 678 sexy, making it appealing," she said. For example, the June/July 2006 "Project 2024" 679 column profiles Christina Norman, who, as the president of MTV, occupies a position 680 that many teen girls would covet. But despite the fact that Norman is a black woman in 681 an industry notorious for its sexism and racism, the story contains no reference to such 682 issues or obstacles. Readers are instead offered tips on how to accomplish their goals and 683 break into the entertainment industry. Norman's advice is to "Speak up for yourself 684 because you are valid. Your needs are valid, what you want is valid, and what you give is 685 valid. You've got to find a way to use your voice to get what you need" (Landy, 2006:

686 123). Norman is put forward as a model, living proof that girls can get to the top through 687 hard work and dedication.

688 This type of discourse, consistent throughout the "Project 2024" profiles, 689 emphasizes the themes of the regular feature - to encourage girls to set goals, believe in 690 themselves, and strive for success in whatever they do. While these are positive 691 messages, a larger feminist framework is replaced by an individualistic, success-oriented 692 "pep talk" that escapes a heavy discussion about the real barriers, such as unequal pay, 693 that women still experience in the workplace. Instead, the columns draw on a fun, 694 fantasy-type "you go girl" narrative that points to the individual's ability to succeed in the 695 capitalist marketplace as the ultimate indicator of feminist empowerment.

696 This dynamic can be seen even more clearly in an editor's discussion of a 2024 697 interview with P.Diddy, whom she cites as one of the "super successful yet sexy at the 698 same time" people they want to cover in the column. While this editor did recognize that 699 sometimes tapping into the celebrity sensibility compromises the broader premise of the 
700 piece, she clearly sees the marketing appeal of the "celebrity" approach as too powerful 701 to resist. The former NYLON editor concurred with this strategy. "I think the best way to 702 approach any political issue with that age group is through some kind of pop culture tie 703 in," she said. "And I think stuff like that makes so much sense - to be able to relate to 704 teenagers on that level, and I don't think there's anything shallow about it or anything 705 wrong with it because that's just what works." With respect to the P.Diddy interview, the 706 CosmoGIRL! editor explained, “Granted, he's a pimp, he's P.Diddy. He's a great role 707 model, but it's not like he's the best. But we're hoping he can give us tricks to basically 708 doing it all and having it all and it's a way to make the initiative seem uber-popular and 709 trendy."

710 While the editors are right that there is nothing inherently wrong with using pop 711 culture and celebrities to popularize feminism in the magazines, the examples given do 712 not seem to include feminism at all. For example, P.Diddy, a music producer and hip hop 713 artist, has never identified as a feminist, nor would his work be considered feminist by 714 most people. Instead it appears as though P.Diddy is being celebrated as a "role model" 715 for his success in the mainstream entertainment industry, for "doing it all and having it 716 all." In this sense it is again individualized success in the capitalist marketplace that is 717 being promoted as feminist empowerment to girls, with no social or structural critiques 718 attached. Furthermore, by characterizing P.Diddy as a "pimp," CosmoGIRL! editors are 719 tapping into the cultural popularity of what Ariel Levy (2005) calls "raunch culture", 720 while ignoring the overtly anti-feminist implications of the "pimp" image. So while 721 readers may have "fun" reading the P.Diddy feature in CosmoGIRL! this does not 722 necessarily mean that feminism is thereby advanced.

723 This obsession with making feminism fun is perhaps the most distinctively third 724 wave tactic that the editors employ. It draws on the third wave's insistence that feminism 725 can and should be a fun force in women's lives, as opposed to a heavy, political 726 responsibility that is more depressing than celebratory (Baumgardner and Richards, 727 2000). One editor reiterated this point when talking about teen magazines. She said, "The 728 main way [teen magazines] express values of the third wave is that they're kind of fun 729 and this is a priority - not a 'girls just wanna have fun' thing - but this idea that women, 
730 not only do they deserve human rights, but they also deserve joy, pleasure, things like 731 that."

732 Here she touches on one of the ongoing feminist debates about glossy teen and 733 women's magazines which was introduced earlier in this article - are they truly vehicles

734 for harmless and even liberatory pleasure, or are they merely reproducing oppressive 735 gender ideology? While it is impossible to definitively settle this debate here, it is worth 736 mentioning how this debate fits into the third wave perspective. From the editors' 737 comments it appears that the third wave emphasizes the pleasurable aspect of reading a 738 magazine and that such magazines can indeed be sources for a popular feminism. Earlier

739 I proposed that a third wave perspective could have the potential to acknowledge the 740 pleasurable aspect of teen magazines, while retaining an ideological critique needed to 741 advance social change. While this potential is indeed exciting, the comments from editors 742 reveal that the content of teen magazines has not yet reached this place, as their examples

743 had little to do with promoting social change, critiquing inequality, or even celebrating

744 the virtues of being a woman beyond the "fun" of wearing lipstick. While using pop

745 culture to make feminism exciting and fun is great, it seems as though the political

746 substance of feminism is at risk of being forgotten in an attempt to make the magazines'

747 content appealing and "fun."

\section{Contradictions}

750 The editors' discussion of their practical strategies revealed that it is a continual

751 task for them to navigate the contradictions of bringing a feminist perspective to

752 mainstream magazines - for example, the frequent instances where feminist content

753 directly collides with anti-feminist content. All of the editors recognized such

754 contradictions as problematic but ultimately accepted them as part of the meeting of

755 feminism and pop culture in a corporate environment. For example, one spoke of writing

756 an in-depth story about body image, only to see the story sandwiched between pictures of

757 Nicole Richie and Mischa Barton, women who, as the editor pointed out, "looked like

758 they had serious eating disorders, and yet, who the magazine was touting as beautiful."

759 Or, again, regarding CosmoGIRL!'s P.Diddy article, the editor recognized that "he's a

760 great role model but it's not like he's the best." She knows that P.Diddy's music, like 
761 mainstream hip hop culture in general, is not exactly "feminist"; however, the magazine 762 accepts these tensions because it ultimately needs to balance what advertisers want, what 763 readers want, and what editors want. Again this illuminates the power that commercial 764 corporations have over the production of magazines (Gill, 2007).

Fashion and beauty spreads were the areas that editors appeared most concerned 766 about from a critical feminist perspective, although (as one argued when speaking about 767 Sassy) editors believe these sections of the magazines can be made more feminist by 768 keeping it fun and offering girls choices. But despite some recent efforts to use "real girl" 769 models and incorporate a diversity of body types into the editorial spreads, skinny models 770 continue to dominate advertising pages and editorial pieces, especially those about 771 celebrities. Editors appear to accept this as a "given," indicating a belief that they have 772 little power to change this aspect of the publication.

773 The contradictions played out in the pages of the magazine may be more 774 acceptable to the editors because they are strongly influenced by third wave feminist 775 ideas (Walker, 1995; Heywood and Drake, 1997; Dicker and Piepmeier, 2003). While 776 feminism has always been complex, encompassing conflicting ideas about such topics as 777 pornography for example, the third wave has truly embraced this "messiness" as one of 778 its defining features. According to Dicker and Piepmeier (2003: 16), "the third wave 779 distinguishes itself from the second wave...through its emphasis on paradox, conflict, 780 multiplicity, and messiness." The editors seem to understand this, and as their interviews 781 suggest, they attempt to incorporate their understanding of a popular feminism into their 782 respective publications, without being too stymied by the contradictions involved in such 783 attempts. "We make sure to keep the 'feel good about yourself' message consistent and 784 try to encourage the girls, you know, 'don't buy into our fashion spreads or the whole 785 skinny model thing,", one editor said. "I believe in my heart though that, this publication 786 in particular, we are giving them some meat, we're feeding them positive messages. It 787 sometimes seems frivolous and it seems fun but underneath it all it's more serious." 788 As I have argued, while many of the topics editors discussed are indeed feminist 789 in nature, the issue of what constitutes a feminist message was often not articulated 790 clearly by the editors. For example, persons who have attained commercial success are 791 put forward as role models, with little attention paid to how they have achieved their 
success, how their success affects others, or what obstacles they may have faced in doing

793 so. While the boundary and meaning of feminism is a larger theoretical problem that

794 third wave feminists must resolve, the unquestioning use of the term "empowerment" by

795 some of the editors may prevent them from undertaking a more critical analysis of their

796 content. This again points to the risk of "feminist free-for-all" wherein almost anything

797 can be claimed as "feminist" without the structural analysis or political rigor that

798 characterizes more traditional feminist critique.

\section{Conclusions}

The previous discussion illuminates some of the tensions created when feminism

805 acknowledged and accepted these contradictions as part of their job and developed

806 specific, practical strategies to incorporate a popular feminism into their publications. I

807 classified these tactics as being indicative of a "third wave ethic," as many of the

808 strategies relied on the tenets of third wave feminism, such as making feminism fun.

809 However, this third wave ethic also influences the content of the magazine, such as in the

810 ways feminism is framed and sold to readers. Primarily, feminism is packaged as a fun

811 celebration of individual agency, with the assurance that choice, hard work, and

812 dedication will lead to success and an empowered, feminist life. To some degree, this can

813 be seen as a truly positive and liberating feminist message - girls can do anything, be

814 anything, and live the dynamic and fulfilling lives that weren't always an option for past

815 generations of women.

816 While an individualistic expression of feminism is not necessarily inherently

817 problematic, by itself it only offers girls a limited understanding of contemporary gender

818 relations. In other words, it is only half of the story that girls need to hear about

819 feminism. This is because the individualized feminism offered by editors overlooks

820 structural barriers such as sexism, racism and classism, important factors that continue to

821 shape the lives of girls. So while editors do rely on particular aspects of the third wave to

822 incorporate feminism into their content, they tend to "cherry pick" and do not incorporate 
823 the structural analysis - the understanding of the barriers facing women as a group - that

824 must inform any effective feminism, no matter of what "wave" it is a part..

825 This structural analysis, although sometimes assumed by critics to be absent from

826 the third wave, is in fact the third wave's political backbone, existing alongside any

827 individualized expressions of feminism (Dicker and Piepmeier, 2003; Baumgardner and

828 Richards, 2000). Dicker and Piepmeier (2003: 18) argue, “As many third wavers realize,

829 it's fine to engage with the world in a playful, individualistic way, but for that

830 engagement to be informed by feminism, it has to take into account the power relations

831 surrounding gender, race, class, and sexual orientation." One group that has done this is

832 the Third Wave Foundation, an organization of self-proclaimed third wavers who work

833 nationally in the United States through strategic grant making, leadership development,

834 and philanthropic advocacy to support equality initiatives for young women and

835 transgender youth, such as the 2009 Latina Health Summit and Young Women's

836 Collaborative. Because this political rigor is conspicuously absent from the feminism

837 found in teen magazines, I question whether feminism framed as "empowerment" and a

838 celebration of individual agency is adequate as a way to promote feminism to a diverse

839 population of girls reading teen magazines.

840 The individualized feminism presented in mainstream teen magazines may be

841 more easily accepted by corporate, mainstream publications because it reinforces larger

842 cultural narratives about hard work, success, and the "American Dream." In this sense,

843 editors appear to be surrendering some of their own independent perspectives by aligning

844 their feminism with a corporate capitalist ideology already accepted by mainstream

845 American society. Thus, their version of popular feminism lacks a critique of capitalism

846 and as a result, fails to incorporate important critiques that have been cornerstones of

847 feminist research, such as those of consumption and the beauty industry, in favor of

848 presenting topics in a playful, "fun" tone. This is problematic because important power

849 hierarchies never get addressed, and the feminism presented is merely stylistic and not

850 geared towards social change.

$851 \quad$ Ultimately, this discussion raises the question of whether individualized

852 feminism, as presented in teen publications, is good or bad for girls and for the future of

853 feminism. Similar debates have engulfed the third wave, as feminists wonder whether the 
854 third wave's individualistic framework tends to pit the advancement of individual women 855 against social change for women as a group. While for some readers, exposure to 856 individualized feminism may be the initial step towards a broader understanding of 857 inequality and social change, this transition would depend on the independent critical 858 thought of readers in linking their own empowerment to that of girls and women as a 859 social group. To examine this possibility, further research would be needed regarding 860 how girls read and interpret third-wave-inspired feminist content in teen magazines. 861 


\section{Acknowledgements}

I would like to thank Dr. Mary Lynn Young and Dr. Dawn Currie at The University of British Columbia for their encouragement, comments, and suggestions while conducting this research. Their insights were invaluable in the shaping of this paper. I would also like to thank the Social Science and Humanities Research Council of Canada for funding this project.

Also thanks to the editors who took time out of their busy schedules to speak with me. I appreciate their honest answers and their participation in this research project.

\section{Reference List}

American Psychological Association. (2007) Report of the APA Task Force on the Sexualization of Girls. Retrieved July 15, 2009 from http://www .apa.org/pi/wpo/sexualization.html.

Bagdikian, B. (1983). The Media Monopoly. Boston: Beacon Press.

(2004). The New Media Monopoly. Boston: Beacon Press.

Baumgardner, J., Richards, A. (2000). Manifesta: Young Women, Feminism, and the Future. New York: Farrar, Straus and Giroux.

Bellafante, G. (1998). It's All About Me!: Want to know what today's chic young feminist thinkers care about? Their bodies! Themselves! Time Magazine (June 29): $54-56$

Bordo, S. (1993). Unbearable Weight: Feminism, Western Culture, and the Body. Berkeley, CA: University of California Press.

Carroll, W (Ed.). (2004). Critical Strategies for Social Research. Toronto: Canadian Scholars' Press Inc.

Currie, D. (1999). Girl Talk: Adolescent Magazines and Their Readers. Toronto: University of Toronto Press. 
Dicker, R. and Piepmeier, A. (Eds.) (2003). Catching a Wave, Reclaiming Feminism for the $21^{\text {st }}$ Century. Boston: Northeastern University Press.

Driscoll, C. (1999). Cyber-gurls, riot grrls, Spice Girls: Girl culture, revenge and global capitalism. Australian Feminist Studies, 14(1), 180-190.

Duke, L. and Kreshel, P. (1998). Negotiating Femininity: Girls in Early Adolescence Read Teen Magazines. Journal of Communication Inquiry. 22 (1), 48-71.

Evans et al.(1991). Content Analysis of Contemporary Teen Magazines for Adolescent Females. Youth and Society . 23 (1), 99-120.

Faludi, S. (1991). Backlash: The Undeclared War against American Women. New York: Crown.

Geraghty, C. (1991). Women and Soap Opera: A Study of Prime Time Soaps. Cambridge: Polity Press.

Gill, R. (2007). Gender and the Media. Cambridge: Polity Press.

Haines, R. (2004). The Problematics of Reclaiming the Girlish: The Powderpuff Girls and Girl Power. FEMSPEC. 5 (2), 1-30.

Henry, A. (2005). Sisters vs. Daughters. In Lorber,J. Gender Inequity: Feminist Theories and Politics, Third Edition (pp. 281-291). Los Angeles: Roxbury.

Herman, E., and Chomsky, N. (1988). Manufacturing Consent: The Political Economy of Mass Media. New York: Pantheon.

Heywood, L and Drake, J. (1997). Third Wave Agenda: Being Feminist, Doing Feminism. Minneapolis: University of Minnesota Press.

Hopkins, S. (2002). Girl Heroes: The New Force In Popular Culture. Australia: Pluto Press.

Jacques, A. (2004) 'Lucky Jupiter Meets Your Ruler': Otherwordly Sources of Girl Power in Magazine Horoscopes. FEMSPEC. 5(2), 45-54.

Jeffreys, S. (2005). Beauty and Misogyny: Harmful Cultural Practices in the West. London: Psychology Press.

Jesella, K. and Meltzer, M. (2007). How Sassy Changed My Life: A Love Letter to the Greatest Teen Magazine of All Time. New York: Farrar, Straus and Giroux.

Karlyn, K.R. (2003). Scream, Popular Culture, and Feminism's Third Wave: “I'm not my 
Mother." Genders Online Journal, Issue 38. Retrieved November 1, 2006 from http://www.genders.org/g38/g38_rowe_karlyn.html.

Kilbourne, J. (1999). The More You Subtract the More You Add: Cutting Girls Down to Size. In Deadly Persuasion (pp. 128-154). New York: Simon and Schuster.

Kirca, S. (2001). Turkish women's magazines: The popular meets the political. Women's Studies International Forum. 24 (3-4), 457-468.

Landy, R. (2006). MTV's MVP. CosmoGIRL! 8 (5), 122-123.

Levy, A. (2005). Female Chauvinist Pigs: Women and the Rise of Raunch Culture. New York: Free Press.

Lorber, J. (2005). Gender Inequality: Feminist Theories and Politics, Third Edition. Los Angeles: Roxbury.

McChesney, R. (2008). The Political Economy of Media: Enduring Issues, Emerging Dilemmas. New York: Monthly Review Press.

McChesney, R. and Foster, J. (2003). The Commercial Tidal Wave. Monthly Review. 54 (10), Retrieved July 10, 2009 from http://www.monthlyreview.org/0303editors.htm.

McRobbie, A. (1978). Jackie: An Ideology of Adolescent Femininity. CCCS occasional paper. Birmingham: University of Birmingham.

(1991). Feminism and Youth Culture. London: Macmillan.

(2009). The Aftermath of Feminism. London: Sage.

Min Online. CosmoGIRL! Retrieved November 7, 2006 from http://www.minonline.com/pq_cosmogirl.htm

Modleski, T. (1982). Loving With A Vengeance: Mass Produced Fantasies for Women. New York: Routledge.

Negra, D. (2009). What a Girl Wants? Fantasizing the reclamation of Self in Postfeminism. New York: Routledge.

Peirce, K. (1990). A Feminist Theoretical Perspective on the Socialization of Teenage Girls Through Seventeen Magazine. Sex Roles. 23 (9/10), 491-501.

Project for Excellence in Journalism. (2004). The State of News Media 2010. Journalism.org. Retrieved June 6, 2010 from www.stateofthenewsmedia.org 
Taft, J. (2004). Girl Power Politics: Pop-Culture Barriers and Organizational Resistance. In Harris, A. (Ed) All About the Girl: Culture, Power, and Identity (pp.69-78). New York: Routledge.

Tuchman, G. (1978). The Symbolic Annihilation of Women in the Media. In Tuchman, G., Daniels, A., and Benet, J. (Eds) Health and Home: Images of Women in the Mass Media. Oxford: Oxford University Press.

Walker, R. (1995). To Be Real: Telling the Truth and Changing the Face of Feminism. New York: Anchor.

Williamson, J. (1978). Decoding Advertisements: Ideology and Meaning in Advertisements. London: Marion Boyars.

Winship, J. (1978). A Woman's World: Woman and Ideology of Feminism. In CCCS Women's Studies Group, Women Take Issue. Birmingham: Hutchinson.

(1991). The Impossibility of Best: Enterprise Meets Domesticity in the Practical Women's Magazines of the 1980s. Cultural Studies. 5(2), 131-56.

Wolf, N. (1991). The Beauty Myth. Toronto: Vintage.

\footnotetext{
${ }^{1}$ Ariel Levy's 2005 book, Female Chauvinist Pigs: Women and the Rise of Raunch Culture, documents the increasing popularity of "raunch culture" in the mainstream. Levy characterizes "raunch culture" as an overt celebration of the sexuality of pornography (like Playboy) and porn culture (like "strippers" and "pimps") and the belief that young women's willing participation in such industries indicates they are liberated and empowered.
} 